\section{(A) Check for updates}

Cite this: Dalton Trans., 2019, 48 15480

\title{
Investigation of the magnetic anisotropy in a series of trigonal bipyramidal Mn(॥) complexes $\uparrow$
}

\author{
Moya A. Hay, (D) a Arup Sarkar, (DD ${ }^{\mathrm{b}}$ Katie E. R. Marriott, ${ }^{\mathrm{a}}$ Claire Wilson, (D) a \\ Gopalan Rajaraman (D) *b and Mark Murrie (D)*a
}

\begin{abstract}
Understanding how the magnetic anisotropy in simple coordination complexes can be manipulated is instrumental to the development of single-molecule magnets (SMMS). Clear strategies can then be designed to control both the axial and transverse contributions to the magnetic anisotropy in such compounds, and allow them to reach their full potential. Here we show a strategy for boosting the magnetic anisotropy in a series of trigonal bipyramidal $\mathrm{Mn}(\mathrm{I})$ complexes - $\left[\mathrm{MnCl}_{3}(\mathrm{HDABCO})(\mathrm{DABCO})\right]$ (1), $\left[\mathrm{MnCl}_{3}(\mathrm{MDABCO})_{2}\right] \cdot\left[\mathrm{ClO}_{4}\right](2)$, and $\left[\mathrm{MnCl}_{3}\left(\mathrm{H}_{2} \mathrm{O}\right)(\mathrm{MDABCO})\right]$ (3). These have been successfully synthesised using the monodentate $[\mathrm{DABCO}]$ and $[\mathrm{MDABCO}]^{+}$ligands. Through static (DC) magnetic measurements and detailed theoretical investigation using ab initio methods, the magnetic anisotropy of each system has been studied. The calculations reveal that the rhombic zero-field splitting (ZFS) term (E) can be tuned as the symmetry around the $\mathrm{Mn}(॥)$ ion is changed. Furthermore, an in silico investigation reveals a strategy to increase the axial ZFS parameter (D) of trigonal bipyramidal Mn(॥) by an order of magnitude.
\end{abstract}

Received 23rd May 2019,

Accepted 27th June 2019

DOI: 10.1039/c9dt02187f

rsc.li/dalton systems to investigate the role of magnetic anisotropy has surged in recent years with changes in both structural and electronic environment altering the ZFS parameters in a noticeable and detectable manner. ${ }^{10}$ Although not expected to exhibit slow relaxation of the magnetisation, due to their essentially isotropic spin ground state, high spin $\mathrm{Mn}^{\mathrm{II}}$ monometallic complexes present an additional opportunity to probe the nature of magnetic anisotropy in certain coordination environments, ${ }^{11,12}$ and magneto-structural correlations can be developed. ${ }^{13-17}$ Here we report an experimental and computational investigation into a series of trigonal bipyramidal $\mathrm{Mn}^{\mathrm{II}}$ monometallic complexes. Furthermore, we propose a strategy for increasing the axial zero-field splitting parameter using magneto-structural correlations developed via ab initio methods. These suggest the potential for an increase in $D$ by an order of magnitude for complexes of this type, which would surpass the current record for $\mathrm{Mn}^{\mathrm{II}}$ mononuclear complexes. ${ }^{18}$

\section{Experimental section}

\section{Materials and physical methods}

All reagents and solvents were obtained from commercial suppliers and used without further purification. The ligand [MDABCO][I] was prepared as previously reported, with minor modifications. ${ }^{13,19}\left[\mathrm{MnCl}_{3}(\mathrm{DABCO})(\mathrm{HDABCO})\right]$ (1) was synthesised following the same method as previously reported. ${ }^{20}$ CAUTION! $\left[\mathrm{ClO}_{4}\right]^{-}$salts are potentially explosive, and so should be handled with care and in small quantities. 
Elemental analysis (EA) was performed in-house by the microanalysis service at the School of Chemistry, University of Glasgow. Additionally, air-sensitive EA was carried out on 2 via the Elemental Analysis Service, University of Strathclyde. IR spectra were collected using a Shimadzu FTIR spectrometer in the range $4000-600 \mathrm{~cm}^{-1}$. Crystallographic data were collected for 1-3 at $100 \mathrm{~K}$ with Mo-K $\alpha$ radiation $(\lambda=0.71073 \AA)$ using a Bruker APEXII CCD diffractometer with an Oxford Cryosystems $n$-Helix low-temperature device mounted on a sealed tube generator. Structures were solved using SHELXT and refined using full-matrix least-squares refinement using Olex $^{2}$ software. $^{21,22}$ The powder X-ray patterns were collected on a PANalytical XPert MPD, with $\mathrm{Cu} K \alpha 1$ radiation at ambient temperature over a range of $5^{\circ}<2 \theta<50^{\circ}$ using a step size of $0.0167^{\circ}$. In each case, the calculated pattern was generated from Mercury using the .cif file of the structure at $100 \mathrm{~K}^{23}$ All magnetic measurements were carried out on powdered crystalline samples restrained in eicosane using a Quantum Design MPMS-XL SQUID magnetometer. The diamagnetic contribution of the sample holder and eicosane were both corrected for by measurements, and the magnetic susceptibility of each sample using Pascal's constants.

\section{Synthetic methods}

[ $\left.\mathrm{MnCl}_{3}(\mathrm{DABCO})(\mathrm{HDABCO})\right]$ (1). To a solution of $\mathrm{MnCl}_{2} \cdot 4 \mathrm{H}_{2} \mathrm{O}(0.40 \mathrm{~g}, 2 \mathrm{mmol})$ in $10 \mathrm{ml}$ of methanol, a colourless solution of DABCO $(0.22 \mathrm{~g}, 2 \mathrm{mmol})$ in methanol $(10 \mathrm{ml})$ was added, resulting in a yellow solution. This solution was stirred at $60{ }^{\circ} \mathrm{C}$ for three hours after which a light brown suspension was obtained which on filtering, once cooled to room temperature, yielded a light brown precipitate and dark brown solution. Single pale-brown block-like crystals suitable for $\mathrm{X}$-ray diffraction were obtained through vapour-liquid diffusion of the solution with diethyl ether. The precipitate was identified as an impure crude product of $\mathbf{1}$ and later discarded as we were unable to obtain a pure crystalline sample on re-dissolving. Yield (crystals) 24\% (96 mg). IR ( $\nu$ in $\left.\mathrm{cm}^{-1}\right)$ : 2965 (w), 2888 (w), 2359 (w), 2332 (w), 1462 (w), 1375 (m), 1323 (m), 1055 (s), 1024 (m), 995 (m), 845 (s), 781 (s), 669 (s). EA analysis: $\left(\mathrm{C}_{12} \mathrm{H}_{25} \mathrm{MnN}_{4} \mathrm{Cl}_{3} \cdot 0.5 \mathrm{H}_{2} \mathrm{O}\right)$ [\%], found: $\mathrm{C} 36.65, \mathrm{H}$ 6.42, N 13.89; calc: C 36.43, H 6.62, N 14.16.

$\left[\mathbf{M n C l}_{3}(\mathrm{MDABCO})_{2}\right] \cdot\left[\mathrm{ClO}_{4}\right]$ (2). To a solution of $\mathrm{MnCl}_{2}$ $(0.13 \mathrm{~g}, 1 \mathrm{mmol})$ in methanol $(10 \mathrm{ml})$, a colourless solution of [MDABCO][I] $(0.52 \mathrm{~g}, 2 \mathrm{mmol})$ and $\mathrm{NaClO}_{4}(0.12 \mathrm{~g}, 1 \mathrm{mmol})$ in methanol $(10 \mathrm{ml})$ was added, resulting in a pale brown solution. This solution was stirred for three hours at $60{ }^{\circ} \mathrm{C}$ before cooling to room temperature. Single colourless block crystals were obtained through vapour-liquid diffusion of the final pale brown solution with diethyl ether. Yield (crystals) 25\% (129 mg). IR ( $\nu$ in $\left.\mathrm{cm}^{-1}\right): 3410(\mathrm{~m}), 3370(\mathrm{w}), 2361(\mathrm{~m}), 1468$ (m), 1078 (s), 1053 (s), 1015 (m), 920 (m), 841 (m), 797 (m), 689 (w), 621 (s). EA analysis: $\left(\mathrm{C}_{14} \mathrm{H}_{30} \mathrm{MnN}_{4} \mathrm{Cl}_{4} \mathrm{O}_{4}\right)$ [\%], found: C 32.65, H 5.87, N 10.51; calc: C 32.64, H 5.87, N 10.88 .

[ $\left.\mathrm{MnCl}_{3}\left(\mathrm{H}_{2} \mathrm{O}\right)(\mathrm{MDABCO})\right]$ (3). To a solution of $\mathrm{MnCl}_{2} \cdot 4 \mathrm{H}_{2} \mathrm{O}$ $(0.20 \mathrm{~g}, 1 \mathrm{mmol})$ in methanol $(10 \mathrm{ml})$, a solution of [MDABCO][I] $(0.26 \mathrm{~g}, 1 \mathrm{mmol})$ in methanol $(10 \mathrm{ml})$ was slowly added and the resulting yellow solution stirred at $60{ }^{\circ} \mathrm{C}$ for 3 hours. Single crystals suitable for X-ray diffraction were obtained after one day through vapour-liquid diffusion of the resulting deep yellow solution with diethyl ether. Yield (crystals) 29\% (89 mg). IR ( $\nu$ in $\left.\mathrm{cm}^{-1}\right): 3405(\mathrm{~s}), 3370(\mathrm{~s}), 2359(\mathrm{~m})$, 1597 (m), 1466 (s), 1114 (s), 1053 (s), 1015 (s), 920 (s), 841 (m), 797 (s), 698 (s). EA analysis: $\left(\mathrm{C}_{7} \mathrm{H}_{17} \mathrm{MnN}_{2} \mathrm{Cl}_{3} \mathrm{O}\right)$ [\%], found: C 27.45, H 5.51, N 8.98; calc: C 27.43, H 5.59, N 9.14.

\section{Results and discussion}

\section{Crystal structure descriptions}

Complex 1 crystallises in the trigonal $R 32$ space group with the corresponding crystallographic data given in Table S1. $\dagger$ The complex has two DABCO moieties coordinated in the axial positions of a central $\mathrm{Mn}^{\mathrm{II}}$, each through a single $\mathrm{N}$ donor (see Fig. 1, left) and with 3 symmetry related $\mathrm{Cl}$ sites occupying the equatorial positions completing the trigonal bipyramidal (TBP) coordination geometry. The $\mathrm{Cl}-\mathrm{Mn}-\mathrm{Cl}, \mathrm{Cl}-\mathrm{Mn}-\mathrm{N}$ and $\mathrm{N}-\mathrm{Mn}-\mathrm{N}$ angles are $120^{\circ}, 90^{\circ}$ and $180^{\circ}$, respectively. Considering the first coordination sphere, the Mn centre possesses $D_{3 \mathrm{~h}}$ symmetry. The asymmetric unit contains $1 / 6$ of a molecule, a $\mathrm{Mn}$ site, a third of a DABCO and one $\mathrm{Cl}$ site with a 3 -fold rotation axis through the $\mathrm{Mn}$ and the $\mathrm{N}$ atoms of the DABCO moieties and 2-fold axes along each of the $\mathrm{Mn}-\mathrm{Cl}$ relating the two DABCO moieties. The shortest intermolecular $\mathrm{Mn} \cdots \mathrm{Mn}$ distance is $7.42 \AA$. There is a strong intermolecular hydrogen bonding interaction $(\mathrm{N} \cdot \mathrm{H}-\mathrm{N})$ with a $\mathrm{N} \cdots \mathrm{N}$ distance of 2.644(7) A pseudo-forming a chain (see Fig. S2†). Note, the position of this proton is clear in the difference Fourier map and the symmetry necessitates it being disordered over two symmetry related half-occupied sites suggesting the hydrogen bonded chains run in both directions along the $c$-axis. SHAPE studies were carried out on complex 1 to quantify the extent of distortion away from the ideal TBP coordination environment. This involved the calculation of continuous shape measures (CShMs) which provides a value corresponding to the agreement of the experimentally obtained atomic positions, and those expected from an ideal polyhedron with the same number of vertices. ${ }^{24}$
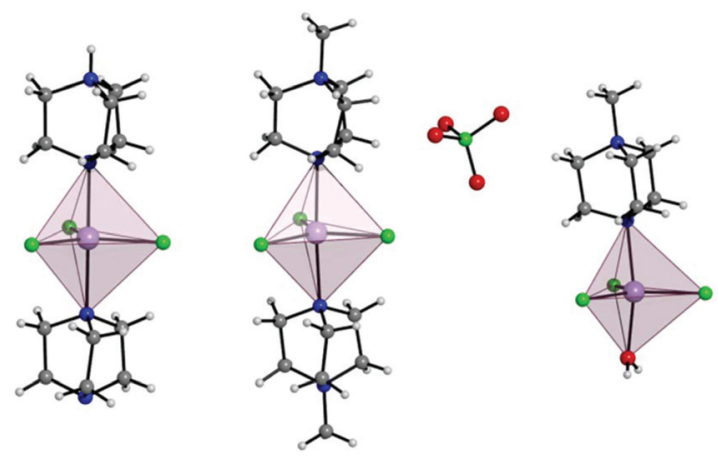

Fig. 1 Depiction of a full molecule of 1 (left), 2 (middle), and 3 (right) with trigonal bipyramidal coordination polyhedra depicted. $\mathrm{C}$, grey; $\mathrm{Cl}$, green; $\mathrm{H}$, white; $\mathrm{Mn}$, lavender; $\mathrm{N}$, blue. 
This then affords the geometry which most closely fits the experimental data obtained, with a value of 0 assigned to an ideal geometry. The results are summarised in Table $\mathrm{S} 4 \dagger$ and confirm a very small distortion away from the ideal trigonal bipyramidal geometry with a CShM value of 0.007 .

The use of $[\mathrm{MDABCO}]^{+}$as a ligand was proposed to change the separation and orientation of the individual molecules in the crystal lattice to establish what impact this change in environment might have on the associated magnetic properties. This resulted in two different structures depending on the $\mathrm{Mn}(\mathrm{II})$ starting material employed: anhydrous $\mathrm{MnCl}_{2}$ leads to $\left[\mathrm{MnCl}_{3}(\mathrm{MDABCO})_{2}\right] \cdot\left[\mathrm{ClO}_{4}\right]$ (2) whereas hydrated $\mathrm{MnCl}_{2}$ leads to $\left[\mathrm{MnCl}_{3}(\mathrm{MDABCO})\left(\mathrm{H}_{2} \mathrm{O}\right)\right]$ (3) as shown in Fig. 1 (see Table $\mathrm{S} 1 \dagger$ for crystallographic data). Complex 2 crystallises in the orthorhombic $\mathrm{Pca}_{1}$ space group and is structurally analogous to the previously reported $\left[\mathrm{NiCl}_{3}(\mathrm{MDABCO})_{2}\right] \cdot\left[\mathrm{ClO}_{4}\right]$ complex. ${ }^{13}$ Complex 3 however crystallises in the lower symmetry monoclinic $P 2_{1} / m$ space group. Similarly to complex $\mathbf{1}$, complex 2 contains a central $\mathrm{Mn}^{\mathrm{II}}$ ion with TBP geometry (confirmed via CShMs) whereby three $\mathrm{Cl}^{-}$ligands are coordinated in the equatorial positions with a $[\mathrm{MDABCO}]^{+}$moiety now occupying each of the axial positions. A perchlorate counter-ion is also present within the asymmetric unit along with a full molecule of 2, with four symmetry related, but differently oriented, molecules present in the unit cell (see Fig. S3†). In the case of complex 3 however, one of the axial positions is instead occupied by a coordinated $\mathrm{H}_{2} \mathrm{O}$. Half a molecule is present within the asymmetric unit and two molecules are aligned antiparallel within the unit cell with respect to their $C_{2}$ mirror planes (see Fig. $\mathrm{S} 4 \dagger$ ). A greater degree of distortion away from the ideal TBP geometry is present in 3 compared to 2 (see Fig. 1 and 2). This increase in distortion is additionally reflected in the bond lengths and angles surrounding the central $\mathrm{Mn}^{\mathrm{II}}$ in 2 and 3 which are summarised in Tables S2 and S3. $\dagger$ Due to the perchlorate counter-ion in 2 , the individual $\left[\mathrm{MnCl}_{3}(\mathrm{MDABCO})_{2}\right]^{+}$cations are further separated within the crystal lattice compared to $\mathbf{1}$, with a minimum intermolecular $\mathrm{Mn} \cdots \mathrm{Mn}$ distance of $8.50 \AA$. This is longer when compared to $\mathbf{1}$ whereas in $\mathbf{3}$, the molecules are able to pack much more closely together with a minimum

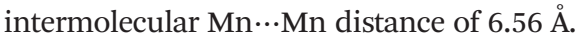

\section{Magnetic properties}

Prior to magnetic measurements, powder X-ray diffraction (PXRD) was used to confirmed phase purity by comparison to
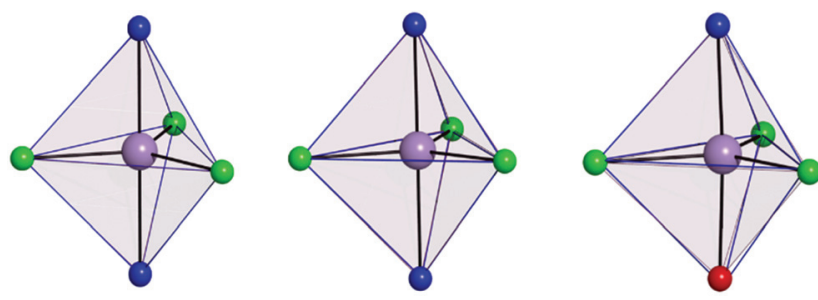

Fig. 2 Coordination polyhedron of the central Mn(॥) of 1 (left), 2 (middle) and 3 (right) shown in pale purple with the closest reference polyhedron for TBP geometry outlined in blue, as calculated using SHAPE. ${ }^{24-26}$ the pattern calculated from the single-crystal data using the software Mercury $^{23}$ (see Fig. S5-S7†). PXRD reveals that upon grinding in air complex 2 decomposes to form complex 3, so for 2 air-sensitive CHN analysis and PXRD techniques were employed and SQUID samples prepared in an Argon-filled glovebox. The variable-temperature magnetic susceptibility data for 1-3 were collected between $290 \mathrm{~K}$ and $2 \mathrm{~K}$ under an applied DC field of 1000 Oe (see Fig. 3). In each case, the measurement was performed on a powdered crystalline sample restrained in eicosane to prevent torqueing or reorientation. At $290 \mathrm{~K}$, all $\chi_{\mathrm{m}} T$ values were in each case slightly higher than that based on the spin only formula value of $4.38 \mathrm{~cm}^{3} \mathrm{~mol}^{-1} \mathrm{~K}$ (where $S=5 / 2, g=2$ ). In all cases, this value slowly decreases until approximately $50 \mathrm{~K}$ after which varying low temperature behaviour is observed. This could be attributed to differences in short-range correlations between molecules within the three different structures. In the case of 1 , two distinct maxima in $\chi_{\mathrm{m}} T$ are observed - at $32 \mathrm{~K}$ and $10 \mathrm{~K}$ reaching values of $4.41 \mathrm{~cm}^{3} \mathrm{~mol}^{-1} \mathrm{~K}$ and $4.36 \mathrm{~cm}^{3} \mathrm{~mol}^{-1}$ $\mathrm{K}$, respectively - with a final minimum value of $3.80 \mathrm{~cm}^{3} \mathrm{~mol}^{-1}$ $\mathrm{K}$ observed at $2 \mathrm{~K}$. No clear maxima are observed for 2 and 3 and after $50 \mathrm{~K}, \chi_{\mathrm{m}} T$ drops off more rapidly due to a small zero-field splitting reaching a minimum value of 3.88 and $1.76 \mathrm{~cm}^{3} \mathrm{~mol}^{-1} \mathrm{~K}$ at $2 \mathrm{~K}$ respectively. The magnetisation measurements ( $M$ vs. $H$ ) were carried out between 0 and $5 \mathrm{~T}$ at 2, 4 and $6 \mathrm{~K}$ on all complexes (see Fig. S8†) and in each case the magnetisation was within range of the expected saturation value of $5.0 N \beta$ at $2 \mathrm{~K}$ with values of $4.9,5.0$ and $4.8 N \beta$ respectively. Attempts to fit the $\chi_{\mathrm{m}} T$ vs. $T$ and $M v s$. $H$ data were carried out using the program $\mathrm{Phi}^{27}$ with the Hamiltonian given in eqn (1).

$$
\hat{H}=D \hat{S}_{z}^{2}+E\left(\hat{S}_{x}^{2}-\hat{S}_{y}^{2}\right)+\mu_{\mathrm{B}} \vec{B} \overleftrightarrow{g} \hat{S}
$$

For complexes 1 and 2 the $\chi_{\mathrm{m}} T$ vs. $T$ data were fitted simultaneously with the $M$ vs. $H$ data (see Fig. 3). For complex 3 fits attempted that included the $M$ vs. $H$ data, either in conjunction with the $\chi_{\mathrm{m}} T$ vs. $T$ data or independently, failed to con-

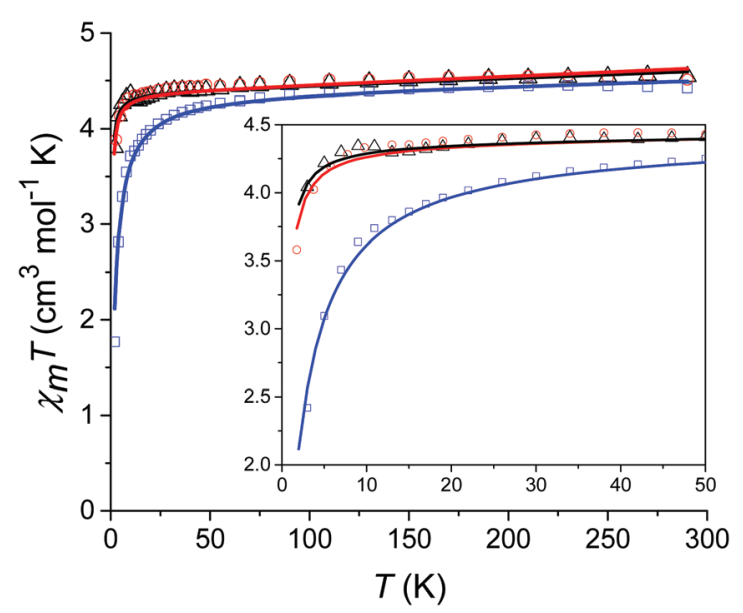

Fig. 3 Temperature dependence of $\chi_{\mathrm{m}} T$ for 1 (black), 2 (red) and 3 (blue) from $290 \mathrm{~K}$ to $2 \mathrm{~K}$ at 1000 Oe with the solid lines corresponding to the respective fits (see text for details). The inset shows the low temperature region $(50-2 \mathrm{~K})$ in more detail. 
Table 1 Parameters used to fit the experimental magnetic data of 1-3: $D$ is fixed and is the sum of spin-orbit $\left(D_{\text {soc }}\right)$ and spin-spin $\left(D_{\text {ss }}\right)$ contributions (vide infra), $E$ and $g$ are fixed at the values obtained from $a b$ initio calculations. The TIP and $z J$ parameters are extracted from the fit (see ESI for more details)

\begin{tabular}{llllll}
\hline & $D\left(\mathrm{~cm}^{-1}\right)$ & $E\left(\mathrm{~cm}^{-1}\right)$ & TIP $\left(\mathrm{cm}^{3} \mathrm{~mol}^{-1}\right)$ & $z J\left(\mathrm{~cm}^{-1}\right)$ & $R(\%)$ \\
\hline 1 & -0.133 & 0 & 0.0008 & -0.013 & 99.9 \\
2 & -0.137 & 0.004 & 0.0009 & -0.017 & 99.7 \\
3 & -0.129 & 0.009 & 0.0005 & -0.126 & 99.7
\end{tabular}

verge. Thus, an optimum fit using only the magnetic susceptibility data for 3 is shown in Fig. 3. In order to improve the fit, the $g$-factor and ZFS parameters were fixed, with values taken from the calculations (see Table 1). Parameters which were then fitted included a temperature independent paramagnetic (TIP) contribution to the susceptibility, which was required to replicate the high temperature data. Note, for high-spin Mn(II) a TIP contribution towards the susceptibility can be present if there are low-lying excited states to which the ground state can mix, ${ }^{28}$ consistent with the results of the $a b$ initio calculations (vide infra). The second parameter determined from the fit was a contribution to the susceptibility from intermolecular interactions $(z J)$ which was required in order to replicate the low temperature data and was necessary for the fit to converge. The magnitude of $z J$ parameters extracted from the fits are similar for both complexes $\mathbf{1}$ and 2, however for complex 3 which has the smallest intermolecular distance between adjacent Mn(II) centres, this value is larger. Both the fixed and fitted parameters are summarised for complexes 1-3 in Table 1.

\section{Theoretical calculations}

Before starting our discussion on the theoretical studies on these three $\mathrm{Mn}$ (II) complexes, we would like to give a brief outline regarding the computational methodology applied here to probe the zero-field splitting. Although these complexes possess a $\mathrm{d}^{5}$ isotropic electronic configuration, small but significant magnetic anisotropy arises from the excited quartet state due to the spin-orbit interaction. Also spin-spin coupling here cannot be ignored. Therefore we computed both the spin-orbit and spin-spin interactions towards the zerofield splitting on these three complexes.

To probe the origin of the magnetic anisotropy of complexes 1-3 arising from spin-orbit interactions we performed CASSCF/NEVPT2 ab initio calculations, which are known to yield accurate estimation of Spin Hamiltonian parameters for such molecules. ${ }^{29-31}$ The high spin $\mathrm{Mn}^{\mathrm{II}}$ ion has a totally symmetric ${ }^{6} \mathrm{~A}_{1}$ ground state and thus is expected to exhibit only a very small zero-field splitting. Calculations yield $D_{\text {SOC }}$ values of $-0.112 \mathrm{~cm}^{-1},-0.113 \mathrm{~cm}^{-1}$ and $-0.108 \mathrm{~cm}^{-1}$ for complexes 1-3, respectively (see Table 2). The computed $g$ anisotropy is found to be isotropic and the estimated value of 2.00 also matches with the experimental magnetic data. Although DFT methods (CP-KS) have successfully predicted the zero-field splitting values for some reported $\mathrm{Mn}$ (II) complexes, ${ }^{12,32,33}$ these methods are proven to be inferior for the estimation of
Table 2 Computed $D_{\mathrm{SOC}}, D_{\mathrm{SS}}, D_{\text {net }}\left(\mathrm{cm}^{-1}\right), E / D$ and $g$-tensors for complexes 1-3

\begin{tabular}{llllll}
\hline & $D_{\text {SOC }}$ & $D_{\text {SS }}$ & $D_{\text {net }}$ & $|E / D|_{\text {SOC }}$ & $g_{\text {iso }}$ \\
\hline 1 & -0.112 & -0.021 & -0.133 & 0 & 2.0 \\
2 & -0.113 & -0.024 & -0.137 & 0.036 & 2.0 \\
3 & -0.108 & -0.021 & -0.129 & 0.079 & 2.0 \\
\hline
\end{tabular}

ZFS parameters. DFT-estimated spin-orbit values for complexes 1-3 are given in Table S8 (see ESI $\dagger$ ) and these values are significantly overestimated when compared to the values obtained from ab initio methods.

The ground sextet state does not contribute to the ZFS and here the ZFS essentially arises due to the spin-flip excited quartet states which are greater than $22000 \mathrm{~cm}^{-1}$ higher in energy compared to the ground state, leading to a small contribution to the $D_{\text {SOC }}$ value (Tables $\mathrm{S} 5-\mathrm{S} 7 \dagger$ ). In the present case, all three complexes are in a trigonal bipyramidal geometry possessing $\sim D_{3 \mathrm{~h}}$ point group symmetry. The computed ground state electronic configuration in all cases is $\mathrm{d}_{x z}{ }^{1} \mathrm{~d}_{y z}{ }^{1} \mathrm{~d}_{x^{2}-y^{2}}{ }^{1} \mathrm{~d}_{x y}{ }^{1} \mathrm{~d}_{z^{2}}{ }^{1}$ and reflects a TBP shape (Fig. 4). The $D_{z Z}$ axis points towards the axial $\mathrm{Mn}-\mathrm{N}$ bond, which is also colinear with the $C_{3}$-axis of the molecule(s).

The $D_{\text {SOC }}$ values of complexes 1-3 are small (around $-0.1 \mathrm{~cm}^{-1}$ ) and here the ZFS arises from several spin-flip excitations. The corresponding equation, which is the sole term contributing to $D$ is given below, ${ }^{29,34}$

$$
\begin{aligned}
D_{\mathrm{KL}}^{\mathrm{SOC}(-1)}= & -\frac{1}{S(2 S-1)} \sum_{I^{\prime}\left(S^{\prime}=S-1\right)} \Delta_{I^{\prime}}{ }^{-1}\left\langle\Psi_{0}^{\mathrm{SS}}\right| \sum_{i} \hat{z}_{\mathrm{K}}(i) \hat{s}_{+1}(i) \\
& \left|\Psi_{I^{\prime}}^{S-1 S-1}\right\rangle\left\langle\Psi_{I^{\prime}}^{S-1 S-1}\left|\sum_{i} \hat{z}_{\mathrm{L}}(i) s_{-1}(i)\right| \Psi_{0}^{\mathrm{SS}}\right\rangle
\end{aligned}
$$

The above equation corresponds to the expression of the $D$ parameter which arises due to the spin value less than one from the ground state spin. Here, $D_{\mathrm{KL}}^{\mathrm{SOC}}$ is the axial ZFS parameter arising from the spin-orbit coupling (SOC) contribution, $S$ is the total spin ground state of $\mathrm{Mn}(\mathrm{II}), \hat{z}_{\mathrm{K}}(i) \hat{s}_{+1}(i)$ is the oneelectron SOC operator and $\Psi$ is the corresponding wavefunction of the system. From Tables S5-S7, $\dagger$ it can be seen that the first two quartet states at $\sim 22000 \mathrm{~cm}^{-1}$ contribute significantly to the $D$ value and their combined contribution is close to $-0.6 \mathrm{~cm}^{-1}$ in all three complexes. The corresponding wavefunctions for these states are given below,

$$
\begin{gathered}
\left|\Psi_{0}^{S=\frac{5}{2}}\right\rangle=\left|\mathrm{d}_{y z}{ }^{1} \mathrm{~d}_{x z}{ }^{1} \mathrm{~d}_{x^{2}-y^{2}}{ }^{1} \mathrm{~d}_{x y}{ }^{1} \mathrm{~d}_{z^{2}}{ }^{1}\right| \\
\left|\Psi_{0}^{S=\frac{3}{2}}\right\rangle=0.76\left|\mathrm{~d}_{y z}{ }^{2} \mathrm{~d}_{x z}{ }^{1} \mathrm{~d}_{x^{2}-y^{2}}{ }^{1} \mathrm{~d}_{x y}{ }^{1} \mathrm{~d}_{z^{2}}{ }^{0}\right| \\
\left|\Psi_{1}^{S=\frac{3}{2}}\right\rangle=0.76\left|\mathrm{~d}_{y z}{ }^{1} \mathrm{~d}_{x z}{ }^{2} \mathrm{~d}_{x^{2}-y^{2}}{ }^{1} \mathrm{~d}_{x y}{ }^{1} \mathrm{~d}_{z^{2}}{ }^{0}\right|
\end{gathered}
$$

The above two wavefunctions in the quartet states $\Psi_{0}$ and $\Psi_{1}$ contribute $76 \%$ each to the overall wavefunctions. The next significant contribution arises from the quartet excited state $\Psi_{9}\left(10^{\text {th }}\right.$ excited state $)$ and it is the same for the three com- 

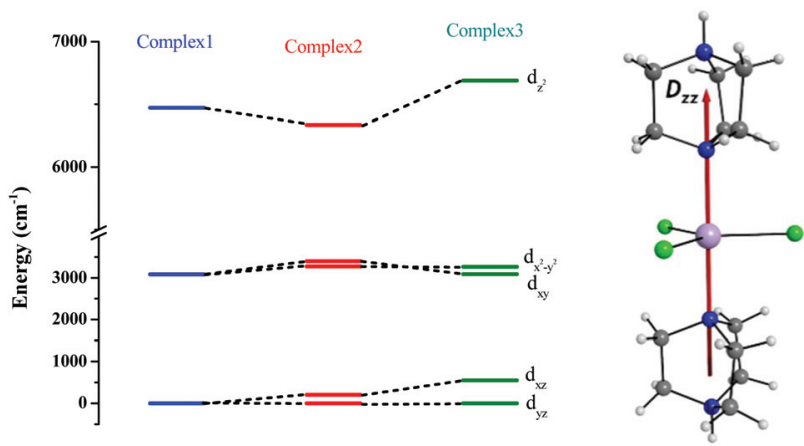

Fig. 4 CASSCF-LFT d-orbital splitting of the ground state in complexes 1,2 and 3, respectively (left). The $D_{\mathrm{zz}}$ anisotropy axis of complex 1 (right).

plexes contributing around $1.5 \mathrm{~cm}^{-1}$ to the overall $D$ value and it constitutes

$$
\begin{aligned}
\left|\Psi_{9}^{S=\frac{3}{2}}\right\rangle= & 0.4\left|\mathrm{~d}_{y z}{ }^{1} \mathrm{~d}_{x z}{ }^{1} \mathrm{~d}_{x^{2}-y^{2}}{ }^{2} \mathrm{~d}_{x y}{ }^{0} \mathrm{~d}_{z^{2}}{ }^{1}\right| \\
& +0.4\left|\mathrm{~d}_{y z}{ }^{1} \mathrm{~d}_{x z}{ }^{1} \mathrm{~d}_{x^{2}-y^{2}}{ }^{0} \mathrm{~d}_{x y}{ }^{2} \mathrm{~d}_{z^{2}}{ }^{1}\right|
\end{aligned}
$$

i.e., a hole created in a $\mathrm{d}_{x y}$ or $\mathrm{d}_{x^{2}-y^{2}}$ orbital respectively. Though this state is $\sim 30000 \mathrm{~cm}^{-1}$ higher in energy compared to the ground state, its contribution is very large compared to the other contributions. Such large positive contributions compensate the negative contributions shown earlier, leading to small net $D$ value for complexes 1-3. Another two significant negative contributions arise from the quartet excited states $\Psi_{15}$ and $\Psi_{16}\left(16^{\text {th }}\right.$ and $17^{\text {th }}$ excited states $)$,

$$
\begin{aligned}
& \left|\Psi_{15}^{S=\frac{3}{2}}\right\rangle=0.48\left|\mathrm{~d}_{y z}{ }^{1} \mathrm{~d}_{x z}{ }^{0} \mathrm{~d}_{x^{2}-y^{2}}{ }^{1} \mathrm{~d}_{x y}{ }^{1} \mathrm{~d}_{z^{2}}{ }^{2}\right| \\
& \left|\Psi_{16}^{S=\frac{3}{2}}\right\rangle=0.48\left|\mathrm{~d}_{y z}{ }^{0} \mathrm{~d}_{x z}{ }^{1} \mathrm{~d}_{x^{2}-y^{2}}{ }^{1} \mathrm{~d}_{x y}{ }^{1} \mathrm{~d}_{z^{2}}\right|
\end{aligned}
$$

These two states contribute $-0.5 \mathrm{~cm}^{-1}$ each to the overall $D$ value. Other than these major contributions, there are also other minor contributions which are very small in magnitude. The $g$ values of these three complexes are totally isotropic in nature, 2.00 , as the $g$ value depends only on the ground electronic state. The sign of $D_{\mathrm{SOC}}$ here cannot be rationalized using the $M_{\mathrm{L}}$ value of the d-orbitals and their excitation, as has been routinely done in other cases, ${ }^{35}$ as here the contributions arise solely due to spin-flip transitions. ${ }^{36}$

Despite the significant structural variations observed, the magnitude of the computed $D$ values is nearly the same in all three complexes. This observation can be rationalized by analyzing the electronic states and their contribution towards the overall $D$ values (Tables S5-S7 in ESI $\dagger$ ). Let us start with complex $\mathbf{1}$, which possesses the highest symmetry $\left(D_{3 \mathrm{~h}}\right)$ among the three complexes (Fig. 4 and Table $54 \dagger$ ) and therefore the first two quartet states are degenerate (Table S5 in ESI $\dagger$ ). These degenerate quartet states contribute equally to the $D$ value. As we move to complexes 2 and 3 , the symmetry is lowered, leading to a lifting of the degeneracy between the $\mathrm{d}_{x z}$ and $\mathrm{d}_{y z}$ and $d_{x^{2}-y^{2}}$ and $d_{x y}$ pairs of orbitals. Furthermore, the separation increases as we go from complex 1 to complex 3 (see Fig. 4). This symmetry consideration is also in agreement with the CShM analysis (Table S4 $\uparrow$ ). As the separation of these orbitals increases, the states which are lower in energy contribute more to the $D$ value while the states which are higher in energy contribute less to the overall $D$ value. Since these two factors compensate each other, the net magnitude of $D$ remains approximately constant across complexes 1-3. The rhombic ZFS $(E)$ values of the three complexes increases from 0 in complex 1 to 0.0041 in complex 2, and 0.0085 in complex 3 (see Table 1). A detailed analysis of the state-wise contribution to the $E$ values (Tables S6 and S7 in ESI $\dagger$ ) suggests a similar pattern of contributions for both complexes 2 and 3, with the main contributions arising from the first two quartet excited states (corresponding wavefunctions are $\left|\Psi_{0}^{S=\frac{3}{2}}\right\rangle$ and $\left|\Psi_{1}^{S=\frac{3}{2}}\right\rangle$ see above) from spin-forbidden $\mathrm{d}_{z^{2}} \rightarrow \mathrm{d}_{x z}$ and $\mathrm{d}_{z^{2}} \rightarrow \mathrm{d}_{y z}$ transitions which give contributions to $E$ of opposite sign. As the symmetry is lower than $D_{3 \mathrm{~h}}$ for complexes $\mathbf{2}$ and $\mathbf{3}$, the $\mathrm{d}_{x z}$ and $\mathrm{d}_{y z}$ orbitals do not remain degenerate (Fig. 4), yielding an overall non-zero $E$ parameter. Complexes 1-3 show that the trigonal symmetry around the $\mathrm{Mn}^{\mathrm{II}}$ ion can be fine-tuned to obtain smaller/larger rhombic ZFS. Importantly, this has potential applications in qubits where a larger rhombic ZFS is desired, as this leads to strong mixing of the states and a greater tunneling probability. ${ }^{37,38}$

While ab initio calculations are known to accurately yield the $D_{\mathrm{SOC}}$ contributions to $D$, the $D_{\mathrm{Ss}}$ contributions are underestimated. ${ }^{29}$ To estimate the $D_{\mathrm{SS}}$ contributions, we have employed density functional methods as this has been shown to yield a good numerical estimate of the $D_{\mathrm{SS}}$ contributions in other examples studied. ${ }^{39}$ The $D_{\mathrm{Ss}}$ values computed using the BP86/TZVP level of theory are $-0.021 \mathrm{~cm}^{-1},-0.024 \mathrm{~cm}^{-1}$, and $-0.021 \mathrm{~cm}^{-1}$ for complexes $1-3$, respectively. The $D_{\mathrm{SS}}$ values are found to be similar for all three complexes and are an order of magnitude smaller than the $D_{\mathrm{SOC}}$ contribution obtained from $a b$ initio calculations. The net sum $D$ values showing $D_{\mathrm{SS}}$ contributions from DFT and $D_{\mathrm{SOC}}$ from $a b$ initio calculations are given in Table S8 (see ESI†).

We have developed magneto-structural correlations in order to increase the axial ZFS (or $D$ value) of the complexes. After analysing the ligand field states, their electronic configurations and their individual contributions to the overall $D$ value, we present an efficient way to fine tune the magnetic anisotropy. The correlation is developed using complex 2 , where we have shortened the Mn-N distances symmetrically from $2.38 \AA$ (experimental) to $1.8 \AA$ artificially in silico. We were encouraged to explore this correlation based on our recent studies on $\left[\mathrm{Ni}(\mathrm{MDABCO})_{2} \mathrm{Cl}_{3}\right] \mathrm{ClO}_{4}$ under high pressure..$^{40}$ Shortening of the $\mathrm{Mn}-\mathrm{N}$ bond distance along the direction where the $\mathrm{d}_{z^{2}}$ orbital lies, leads to destabilization of this orbital, and assuming a dominant $\sigma$ interaction of the ligand, the energies of the $d_{x z}$ and $\mathrm{d}_{y z}$ orbitals are unaltered. The destabilization of the $\mathrm{d}_{z^{2}}$ orbital effectively favours this electron to be paired up with the 


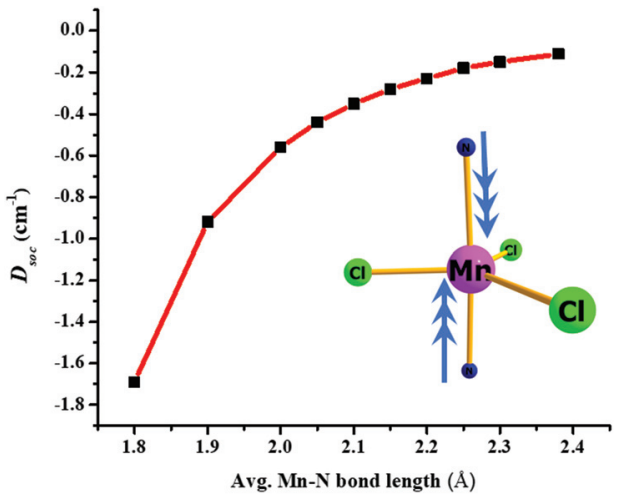

Fig. 5 Magneto-structural correlation of $\mathrm{Mn}-\mathrm{N}$ bond length with $D_{\mathrm{SOC}}$ values for complex 2 .

lowest $\mathrm{d}_{x z} / \mathrm{d}_{y z}$ orbitals: this decreases the energy of the corresponding first and second excited quartet states, with the shortest Mn-N distances leading to a smaller sextet-quartet gap. This energy lowering of the first two quartet states results in an increase of the $D_{\mathrm{SOC}}$ value in the computed data (see Fig. 5 and Fig. S14 $\dagger$ ). The $D_{\text {SOC }}$ value is found to increase by an order of magnitude in complex 2 to $-1.69 \mathrm{~cm}^{-1}$ in the model complex for a Mn-N distance of $1.8 \AA$ (see Table S9, ESI†). This suggests that the magnitude of the $D$ value could be further enhanced in trigonal bipyramidal high-spin $\mathrm{d}^{5}$ systems by using stronger $\mathrm{N}$-donor ligands in the axial positions to reduce the metal-N distances.

\section{Conclusions}

Three mononuclear trigonal bipyramidal $\mathrm{Mn}^{\mathrm{II}}$ complexes have been successfully synthesised, $\left[\mathrm{MnCl}_{3}(\mathrm{HDABCO})(\mathrm{DABCO})\right](\mathbf{1})$, $\left[\mathrm{MnCl}_{3}(\mathrm{MDABCO})_{2}\right] \cdot\left[\mathrm{ClO}_{4}\right](2)$, and $\left[\mathrm{MnCl}_{3}\left(\mathrm{H}_{2} \mathrm{O}\right)(\mathrm{MDABCO})\right](3)$. $A b$ initio and density functional calculations performed on complexes 1-3 provided the ZFS parameters that were then used to successfully fit the dc magnetic data. In addition, the $a b$ initio calculations were used to rationalise the increase in rhombic ZFS across the series. Inspired by our previous work on the $\mathrm{Ni}^{\mathrm{II}}$ analogue of 2 we have shown a potential route to increase the axial magnetic anisotropy in mononuclear $\mathrm{d}^{5}$ systems of this type. This is based on magneto-structural correlations, and achieved through shortening of the axial bond lengths $\left(\mathrm{N}-\mathrm{Mn}-\mathrm{N}^{\prime}\right)$ in silico, which predict a $>10$-fold increase in $D$ from the values reported for 1-3. Synthetic efforts towards related trigonal bipyramidal complexes where stronger $\sigma$-donors reside in both axial positions and/or heavier ligands such as $\mathrm{Br}$ that reside in the equatorial positions, which could increase spin-orbit effects and increase $D$, would be interesting. This should result in a shortening of the axial bonds and thus to an increase in the axial ZFS parameter.

\section{Conflicts of interest}

There are no conflicts to declare.

\section{Acknowledgements}

We would like to thank the University of Glasgow and the UK Engineering and Physical Sciences Research Council for financial support (grant ref. EP/J018147/1, EP/K033662/1 and EP/ M508056/1). GR would like to thank SERB for funding (CRG/ 2018/000430). Arup would like to thank CSIR for SRF fellowship and NPSF CDAC for HPC facility at Pune. The relevant data corresponding to this work is available at http://dx.doi. org/10.5525/gla.researchdata.840.

\section{Notes and references}

1 D. Gatteschi, R. Sessoli and J. Villain, Molecular Nanomagnets, OUP Oxford, Oxford, 2006.

2 G. Christou, D. Gatteschi, D. N. Hendrickson and R. Sessoli, MRS Bull., 2000, 25, 66-71.

3 R. Sessoli, H. L. Tsai, A. R. Schake, S. Wang, J. B. Vincent, K. Folting, D. Gatteschi, G. Christou and D. N. Hendrickson, J. Am. Chem. Soc., 1993, 115, 18041816.

4 R. Sessoli, D. Gatteschi, A. Caneschi and M. A. Novak, Nature, 1993, 365, 141-143.

5 C. J. Milios, A. Vinslava, W. Wernsdorfer, S. Moggach, S. Parsons, S. P. Perlepes, G. Christou and E. K. Brechin, J. Am. Chem. Soc., 2007, 129, 2754-2755.

6 Y. C. Chen, J. L. Liu, L. Ungur, J. Liu, Q. W. Li, L. F. Wang, Z. P. Ni, L. F. Chibotaru, X. M. Chen and M. L. Tong, J. Am. Chem. Soc., 2016, 138, 2829-2837.

7 M. Affronte, F. Troiani, A. Ghirri, A. Candini, M. Evangelisti, V. Corradini, S. Carretta, P. Santini, G. Amoretti, F. Tuna, G. Timco and R. E. P. Winpenny, J. Phys. D: Appl. Phys., 2007, 40, 2999.

8 L. Bogani and W. Wernsdorfer, Nat. Mater., 2008, 7, 179186.

9 G. A. Craig and M. Murrie, Chem. Soc. Rev., 2015, 44, 21352147.

10 S. Gómez-Coca, D. Aravena, R. Morales and E. Ruiz, Coord. Chem. Rev., 2015, 289-290, 379-392.

11 C. Duboc, Chem. Soc. Rev., 2016, 45, 5834-5847.

12 S. Zein, C. Duboc, W. Lubitz and F. Neese, Inorg. Chem., 2008, 47, 134-142.

13 K. E. R. Marriott, L. Bhaskaran, C. Wilson, M. Medarde, S. T. Ochsenbein, S. Hill and M. Murrie, Chem. Sci., 2015, 6, 6823-6828.

14 W. H. Harman, T. D. Harris, D. E. Freedman, H. Fong, A. Chang, J. D. Rinehart, A. Ozarowski, M. T. Sougrati, F. Grandjean, G. J. Long, J. R. Long and C. J. Chang, J. Am. Chem. Soc., 2010, 132, 18115-18126.

15 Y. Rechkemmer, F. D. Breitgoff, M. van der Meer, M. Atanasov, M. Hakl, M. Orlita, P. Neugebauer, F. Neese, B. Sarkar and J. van Slageren, Nat. Commun., 2016, 7, 10467.

16 J. Krzystek and J. Telser, Dalton Trans., 2016, 45, 1675116763. 
17 P. Comar, T. Rajeshkumar, G. S. Nichol, M. B. Pitak, S. J. Coles, G. Rajaraman and E. K. Brechin, Dalton Trans., 2015, 44, 19805-19811.

18 C. Pichon, P. Mialane, E. Rivière, G. Blain, A. Dolbecq, J. Marrot, F. Sécheresse and C. Duboc, Inorg. Chem., 2007, 46, 7710-7712.

19 J. V. Quagliano, A. K. Banerjee, V. L. Goedken and L. M. Vallarino, J. Am. Chem. Soc., 1970, 92, 482-488.

20 R. G. Pritchard, M. Ali, A. Munim and A. Uddin, Acta Crystallogr., Sect. C: Cryst. Struct. Commun., 2006, 62, m507-m509.

21 O. V. Dolomanov, L. J. Bourhis, R. J. Gildea, J. A. K. Howard and H. Puschmann, J. Appl. Crystallogr., 2009, 42, 339-341.

22 G. M. Sheldrick, Acta Crystallogr., Sect. A: Found. Adv., 2015, 71, 3-8.

23 C. F. Macrae, P. R. Edgington, P. McCabe, E. Pidcock, G. P. Shields, R. Taylor, M. Towler and J. Van De Streek, J. Appl. Crystallogr., 2006, 39, 453-457.

24 M. Pinsky and D. Avnir, Inorg. Chem., 1998, 37, 5575-5582.

25 D. Casanova, J. Cirera, M. Llunell, P. Alemany, D. Avnir and S. Alvarez, J. Am. Chem. Soc., 2004, 126, 1755-1763.

26 S. Alvarez, Chem. Rev., 2015, 115, 13447-13483.

27 N. F. Chilton, R. P. Anderson, L. D. Turner, A. Soncini and K. S. Murray, J. Comput. Chem., 2013, 34, 1164-1175.

28 R. Boča, Theoretical Foundations of Molecular Magnetism, Elsevier Science, 1999.
29 M. Atanasov, D. Aravena, E. Suturina, E. Bill, D. Maganas and F. Neese, Coord. Chem. Rev., 2015, 289-290, 177-214.

30 S. S. Kumar, G. Tulika, B. Prashi and R. Gopalan, Chem. Eur. J., 2014, 20, 10305-10313.

31 A. Sarkar, G. Velmurugan, T. Rajeshkumar and G. Rajaraman, Dalton Trans., 2018, 47, 9980-9984.

32 C. Duboc, T. Phoeung, S. Zein, J. Pécaut, M.-N. Collomb and F. Neese, Inorg. Chem., 2007, 46, 4905-4916.

33 S. Zein and F. Neese, J. Phys. Chem. A, 2008, 112, 79767983.

34 F. Neese and E. I. Solomon, Inorg. Chem., 1998, 37, 65686582.

35 T. Gupta and G. Rajaraman, Chem. Commun., 2016, 52, 8972-9008.

36 S. K. Singh and G. Rajaraman, Nat. Commun., 2016, 7, 10669-10676.

37 M. S. Fataftah, J. M. Zadrozny, S. C. Coste, M. J. Graham, D. M. Rogers and D. E. Freedman, J. Am. Chem. Soc., 2016, 138, 1344-1348.

38 M. S. Fataftah, S. C. Coste, B. Vlaisavljevich, J. M. Zadrozny and D. E. Freedman, Chem. Sci., 2016, 7, 6160-6166.

39 F. Neese, J. Am. Chem. Soc., 2006, 128, 10213-10222.

40 G. A. Craig, A. Sarkar, C. H. Woodall, M. A. Hay, K. E. R. Marriott, K. V. Kamenev, S. A. Moggach, E. K. Brechin, S. Parsons, G. Rajaraman and M. Murrie, Chem. Sci., 2018, 9, 1551-1559. 